Summary: The aim of this work is the production of fibers from biodegradable polymers to obtain 3D scaffolds for tissue engineering of hard tissues. The scaffolds required for this highly demanding application need to have, as well as the biological and mechanical characteristics, a high degree of porosity with suitable dimensions for cell seeding and proliferation. Furthermore, the open cell porosity should have adequate interconnectivity for a continuous flow of nutrients and outflow of cell metabolic residues as well as to allow cell growth into confluent layers. Blends of corn starch, a natural biodegradable polymer, with other synthetic polymers (poly(ethylene vinyl alcohol), poly( $\varepsilon$-caprolactone), poly(lactic acid)) were selected for this work because of their good balance of properties, namely biocompatibility, processability and mechanical properties. Melt spinning was used to produce fibers from all the blends and 3D meshes from one of the starchpoly(lactic acid) blends. The experimental characterization included the evaluation of the tensile mechanical properties and thermal properties of the fibers and the compression stiffness, porosity and degradation behavior of the $3 \mathrm{D}$ meshes.

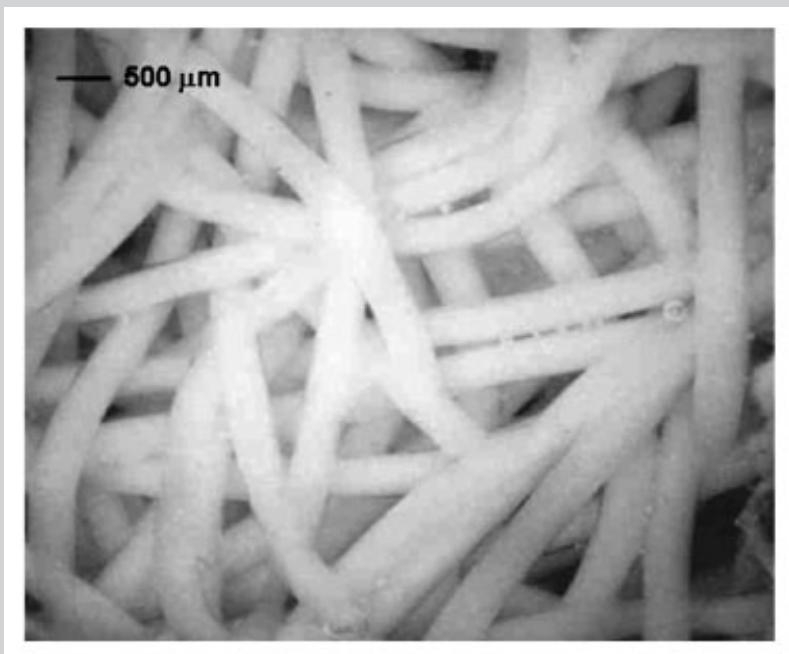

Light microscopy picture of 3D meshes.

\title{
Fibers and 3D Mesh Scaffolds from Biodegradable Starch-Based Blends: Production and Characterization
}

\author{
Miroslav P. Pavlov, ${ }^{1,2}$ João F. Mano, ${ }^{1,2}$ Nuno M. Neves, ${ }^{1,2}$ Rui L. Reis ${ }^{1,2}$ \\ ${ }^{1}$ Department of Polymer Engineering, University of Minho, Campus of Azurem, 4800-058 Guimaraes, Portugal \\ E-mail: nuno@dep.uminho.pt \\ 23B's Research Group in Biomaterials, Biodegradables and Biomimetics, University of Minho, Campus de Gualtar, \\ 4710-057 Braga, Portugal
}

Received: January 2, 2004; Revised: March 16, 2004; Accepted: March 17, 2004; DOI: 10.1002/mabi.200400002

Keywords: biodegradable; fibers; mechanical properties; scaffolds for tissue engineering

\section{Introduction}

The advent of tissue engineering as a new research field has led to the challenge of producing tissue substitutes which are able to restore or regenerate the human functional and physiological characteristics of in vivo tissues. ${ }^{[1,2]}$ This ambitious goal requires interdisciplinary research strategies combining expertise from biology, chemistry, engineering and materials science. The vision and the research in this field is aimed at being able to produce human functional organs in order to overcome the problems associated with the shortage of organs available for transplantation and the problems associated with the immune response of the organism to allograft tissues and implantable materials. The approach that has been proposed starts by collecting some of the patients cellular material (typically by means of a small biopsy). The cellular material can be from embryonic cells, the cells of an adult organ or even native cellular tissue. From this cellular material it is necessary to collect and isolate the target cells that differentiate into the phenotype that leads to the tissue under development or to isolate multipotent stem cells. The cells are further expanded and differentiated into the required amount of cells and phenotypic expression in vitro by means of providing appropriate culture environments. These environments may include cocktails of growth factors or other stimuli (mechanical, chemical or electrical). The developed constructs are then implanted back into the patient, restoring the organ functional characteristics.

The materials commonly used for tissue engineering include ceramics, polymers or composites. The ceramics and polymers are either resorbable or non-resorbable and 
the polymers can be natural or synthesized. ${ }^{[2]}$ In most cases, biocompatible and biodegradable polymers are utilized to induce surrounding tissue ingrowth or to serve as temporary scaffolds for culture cells to attach to, proliferate and maintain differentiated function. ${ }^{[3-9]}$

This research work is directed towards the production of fibers from biodegradable polymers to obtain 3D scaffolds for tissue engineering. A blend of starch with poly(lactic acid) was selected for this work because of its well balanced properties including biocompatibility, degradability, mechanical properties and melt processability.

Previously, various processing techniques have been used to produce scaffolds such as solvent casting, ${ }^{[4,10]}$ particulate leaching, ${ }^{[3,4,10]}$ membrane lamination, ${ }^{[4]}$ highpressure-based methods ${ }^{[4]}$ melt-based technologies ${ }^{[11]}$ or microwave baking. ${ }^{[12]}$ The major limitation of the scaffolds produced by those methods is their relatively limited mechanical properties, hindering their use in hard tissue regeneration where the required stiffness and strength are high. ${ }^{[9,13]}$ In this work we have developed fibers of biodegradable polymers and 3D porous scaffolds based on them. The processing routines used were based on the meltspinning technique. Melt-spinning is a process in which a viscous melt is extruded through a contraction nozzle (normally with a circular cross-section) and then further strained during cooling to align the material in the axis of the fiber. ${ }^{[14]}$

The advantages of melt-spun fibers in comparison with solvent spun fibers include higher specific strength, even wall thickness and the required temperature and chemical resistance of the polymer. Those characteristics are of special interest for both technical and medical applications.

A schematic representation of the spinning apparatus adapted from a capillary rheometer is shown in Figure 1.

Fibers with enhanced mechanical properties are obtained by keeping the rotating speed of the winder much higher than the extrusion speed (controlled by the piston speed). The production of fibers with good mechanical properties could allow for the development of 3D scaffolds with an enhanced mechanical performance.

\section{Materials and Methods}

\section{Materials}

The polymers used in this work were based on blends of corn starch with: (i) ethylene vinyl alcohol (SEVA-C 50/ 50 wt.-\%); (ii) $\varepsilon$-caprolactone (PCL 70 wt.-\%); two different blends depending on the amount of poly(lactic acid): (iii) 50 wt.-\% poly(lactic acid) (SPLA 50) and (iv) $70 \mathrm{wt} . \%$ poly(lactic acid) (SPLA 70). All the materials were supplied by Novamont, Italy.

Other materials used in this work were a blowing agent containing sodium bicarbonate from Nabisco, Spain and hydrogen peroxide $\left(\mathrm{H}_{2} \mathrm{O}_{2}\right)$ from Panreac Quimica SA, Spain.

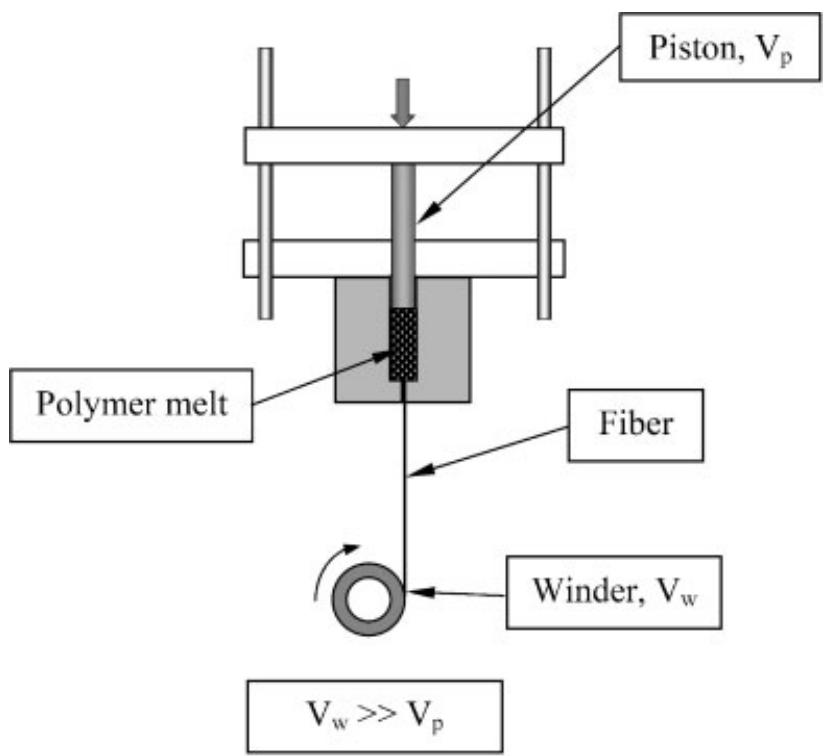

Figure 1. Schematic representation of the spinning set-up adapted in the capillary rheometer.

\section{Methods}

The experimental plan included the preparation of fibers of starch based polymeric blends using a capillary rheometer Rosand RH 8-2. The equipment was chosen because the processing procedure was simple, being similar to the extrusion process, and it was easily adapted for the production of fibers by melt-spinning. It was also intended to minimize the thermal cycle to which the melt was subjected, avoiding thermal degradation as much as possible.

To find the most suitable conditions, a screening study was carried out looking at various processing parameters such as temperature, die diameter and extrusion speed and different combinations of them. The sets of parameters used in the screening study are compiled in Table 1 .

The conditions that were selected to effectively produce stretched and non-stretched fibers are shown in Table 2.

The extruded polymeric monofilaments were additionally stretched using a rotating tool with a constant rotating speed which was always larger than the extrusion speed.

3D scaffolds were produced from the most promising fibers, SPLA 70 fibers, the selection being based on the

Table 1. Preliminary conditions used to produce starch based polymeric fibers.

Corn starch based Processing Die's diameter Extrusion speed polymer blend temperature

\begin{tabular}{|c|c|c|c|}
\hline & ${ }^{\circ} \mathrm{C}$ & $\mathrm{mm}$ & $\mathrm{mm} \cdot \mathrm{min}^{-1}$ \\
\hline SPCL & $130-180$ & $0.5 ; 1.0 ; 2.0$ & $20 ; 15 ; 10 ; 5 ; 3.5 ; 2$ \\
\hline SPLA 70 & $140-175$ & $0.5 ; 1.0 ; 2.0$ & $20 ; 15 ; 10 ; 5 ; 3.5 ; 2$ \\
\hline SPLA 50 & $130-175$ & $0.5 ; 1.0 ; 2.0$ & $20 ; 15 ; 10 ; 5 ; 3.5 ; 2$ \\
\hline SEVA-C & $170-190$ & $0.5 ; 1.0 ; 2.0$ & $20 ; 15 ; 10 ; 5 ; 3.5 ; 2$ \\
\hline
\end{tabular}


Table 2. The optimized conditions used to produce stretched fibers.

\begin{tabular}{|c|c|c|c|}
\hline \multirow[t]{2}{*}{$\begin{array}{l}\text { Corn starch based } \\
\text { polymer blend }\end{array}$} & $\begin{array}{l}\text { Processing } \\
\text { temperature }\end{array}$ & Die's diameter & $\begin{array}{l}\text { Extrusion } \\
\text { speed }\end{array}$ \\
\hline & ${ }^{\circ} \mathrm{C}$ & $\mathrm{mm}$ & $\mathrm{mm} \cdot \min ^{-1}$ \\
\hline SPCL & 175 & 0.5 & 3.5 \\
\hline SPLA 70 & 165 & 1.0 & 5.0 \\
\hline SPLA 50 & 165 & 1.0 & 10.0 \\
\hline SEVA-C & 175 & 0.5 & 3.5 \\
\hline
\end{tabular}

mechanical properties (higher modulus and strength). The procedure used in the production of 3D porous scaffolds was also very simple. The fibers were extruded directly into a cylindrical container with $5 \mathrm{~cm}$ diameter and $2 \mathrm{~cm}$ height. The weight of the fibers and the fact that they were still hot enough provided the necessary conditions to obtain a porous but compact mesh. Further testing of these meshes was carried out using sectioned specimens of $10 \times 10 \times 20 \mathrm{~mm}^{3}$.

\section{Experimental Characterization Routine Used for the Fibers}

The fibers were characterized using a wide range of techniques, namely light microscopy, scanning electron microscopy, differential scanning calorimetry, degradation tests and tensile tests.

\section{Light Microscopy}

The characterization of the fibers' diameter was carried out using a Light reflection microscope, OLYMPUS SZ-PT, and the image analysis software QUANTIMET 500 from LEICA. The diameter was measured in five different locations for three fiber batches of each type.

\section{Scanning Electron Microscopy (SEM)}

A Scanning electron microscope (LEICA Cambridge 5360, England) was used to determine eventual surface defects. The typical magnification that was used was 8000 .

\section{Differential Scanning Calorimetry (DSC)}

DSC experiments on the fibers produced were performed using a Perkin-Elmer DSC 7 apparatus. The tests allowed the melting temperature $\left(T_{\mathrm{m}}\right)$, melting enthalpy $\left(\Delta H_{\mathrm{m}}\right)$, glass transition temperature $\left(T_{\mathrm{g}}\right)$ and change in heat capacity during the glass transition $\left(\Delta C_{\mathrm{p}}\right)$ to be determined. The total degree of crystallization $\left(W_{\mathrm{c}}\right)$ in the synthetic component was estimated using

$$
W_{\mathrm{c}}=\left(\Delta H_{\mathrm{m}} / \Delta H_{0}\right) F
$$

where $\Delta H_{\mathrm{m}}$ is the experimental melting heat, $\Delta H_{0}$ is the melting heat of a $100 \%$ crystal polymer and $F$ is the weight fraction of the synthetic component in the blend.

The samples were placed in aluminum pans and heated at a rate of $10^{\circ} \mathrm{C} \mathrm{min}-1$ from 20 to $180^{\circ} \mathrm{C}$ for SPLA 50, SPLA 70 and SEVA-C and from 20 to $100^{\circ} \mathrm{C}$ for SPCL. Standard calibrations (temperature and heat flux) were performed using indium and lead.

\section{Degradation Tests}

The degradation behavior of three different samples was tested in isotonic saline solution $(0.154 \mathrm{~m} \mathrm{NaCl}, \mathrm{pH}=7.4$, room temperature) for several immersion periods. The specimens were rinsed and weighed after 2, 5, 20, 48 and $96 \mathrm{~h}$. The next step was the determination of the weight loss. Every specimen was dried for $4 \mathrm{~d}$ at $60^{\circ} \mathrm{C}$. Another part of these specimens was dried in a desiccator up to constant weight to be tensile tested in order to evaluate the changes in the mechanical properties as a function of the degradation time.

\section{Tensile Tests}

For characterization of the mechanical properties, stretched and non-stretched fibers were tensile tested. The secant modulus at $1 \%$ strain, tensile strength at break and strain at break were determined. These tests were performed using an Instron 4505 universal mechanical testing machine at $24^{\circ} \mathrm{C}$ and a humidity of $56 \%$. The crosshead speed was $10 \mathrm{~mm} \cdot \mathrm{min}^{-1}$ and a $2.5 \mathrm{~N}$ load cell was used. Specimens $10 \mathrm{~cm}$ long were cut from the continuous monofilaments produced and further used in the mechanical tests.

\section{Characterization of the 3D Porous Scaffolds}

\section{Light Microscopy}

The evaluation of the porosity was performed by light microscopy using a light reflection microscope, OLYMPUS SZ-PT, and image analysis software QUANTIMET 500 from LEICA. Both the total porosity and the interconnected porosity were evaluated. The porosity measurements were based on the area of the whole picture and on the area of the pores, respectively.

\section{Degradation Tests}

An isotonic saline solution $(0.154 \mathrm{MNaCl}, \mathrm{pH}=7.4$, room temperature) was used as a degradation media. At the end of each immersion period the samples were removed from the solution and following the procedure described previously the water uptake and the weight loss were determined. Another part of these samples was dried in a desiccator up to the point at which a moisture content equilibrium was reached. The equilibrium point was determined when a constant weight was achieved. The specimens were then mechanically tested.

\section{Results and Discussion}

\section{Fiber Characterization}

\section{Fiber Diameter}

Table 3 shows that the fibers made of SPCL have the smallest diameter, as a result of their higher flexibility, i.e. it was possible to stretch them more than the other blends. At the other extreme, it was not possible to stretch SPLA 50 fibers without breaking them. The most promising material was SPLA 70, with fiber diameters ranging between those of SPCL and SEVA-C, which exhibited higher mechanical 
Table 3. Average diameter of the fibers produced from different starch based polymers.

\begin{tabular}{|c|c|c|}
\hline \multirow[t]{2}{*}{ Sample } & $\begin{array}{l}\text { Diameter measured by } \\
\text { light microscopy }\end{array}$ & $\begin{array}{c}\text { Diameter measured } \\
\text { by SEM }\end{array}$ \\
\hline & $\mu \mathrm{m}$ & $\mu \mathrm{m}$ \\
\hline SPCL fibers & 150 & 156 \\
\hline SPLA 70 fibers & 214 & 190 \\
\hline SEVA-C fibers & 480 & 450 \\
\hline SPLA 50 fibers & 480 & 476 \\
\hline
\end{tabular}

properties (modulus and strength) than SPCL, SPLA 50 and SEVA-C.

\section{Differential Scanning Calorimetry (DSC)}

The results from DSC for stretched and for the initial material (non-processed) are shown in Figure 2. The melting of the synthetic phase was clearly detected for all the thermoplastic materials (endothermic peak), but in the temperature range studied, glass transitions were only observed in SPLA50 and SPLA70.

Table 4 summarizes the characteristics of the thermal transitions detected in the materials. It was consistently observed that the materials had a higher crystalline content after processing. Thus, the processing induced additional crystallization, possibly resulting from molecular sliding and friction during extrusion and subsequent stretching. ${ }^{[15]}$ The most expressive situation was observed in the two SPLAs, when compared with SPCL and SEVA-C. After processing, the crystalline fraction of SPLA 70 is around 10 times larger than in the non-stretched samples. Also for SPLA 50, the crystallinity level after processing is almost fifteen times higher than before processing. The increase of the crystalline phase upon stretching can also be observed by the decrease of $\Delta C_{\mathrm{p}}$ of the stretched fibers, indicating a smaller amount of the amorphous fraction. The material which showed the least crystallization sensitivity in stretching was SPCL.

For SPLA 50 and SPLA 70, two overlapping processes were detected in the endothermic melting peaks. A possible explanation was proposed by Mani et al. ${ }^{[16]}$ They stated that this could be caused by the existence of crystals with different sizes resulting from crystal thickening during the experiment. Such a bimodal nature is more obvious in the case of SPLA 70 than SPLA 50 due to the higher PLA content in SPLA 70.

The formation of hydrogen bonds between the hydroxyls of starch and carbonyl of PCL at the interface region and their effect on PCL crystallites can explain the slight decrease in the melt temperature when comparing pure PCL $\left(64.8^{\circ} \mathrm{C}\right)^{[17]}$ and SPCL (ca. $\left.54^{\circ} \mathrm{C}\right)$. Such interactions between PCL and starch may lead to less perfect crystallites (thinner lamellae), decreasing the melting temperature of the synthetic polymer. The same explanations could be used
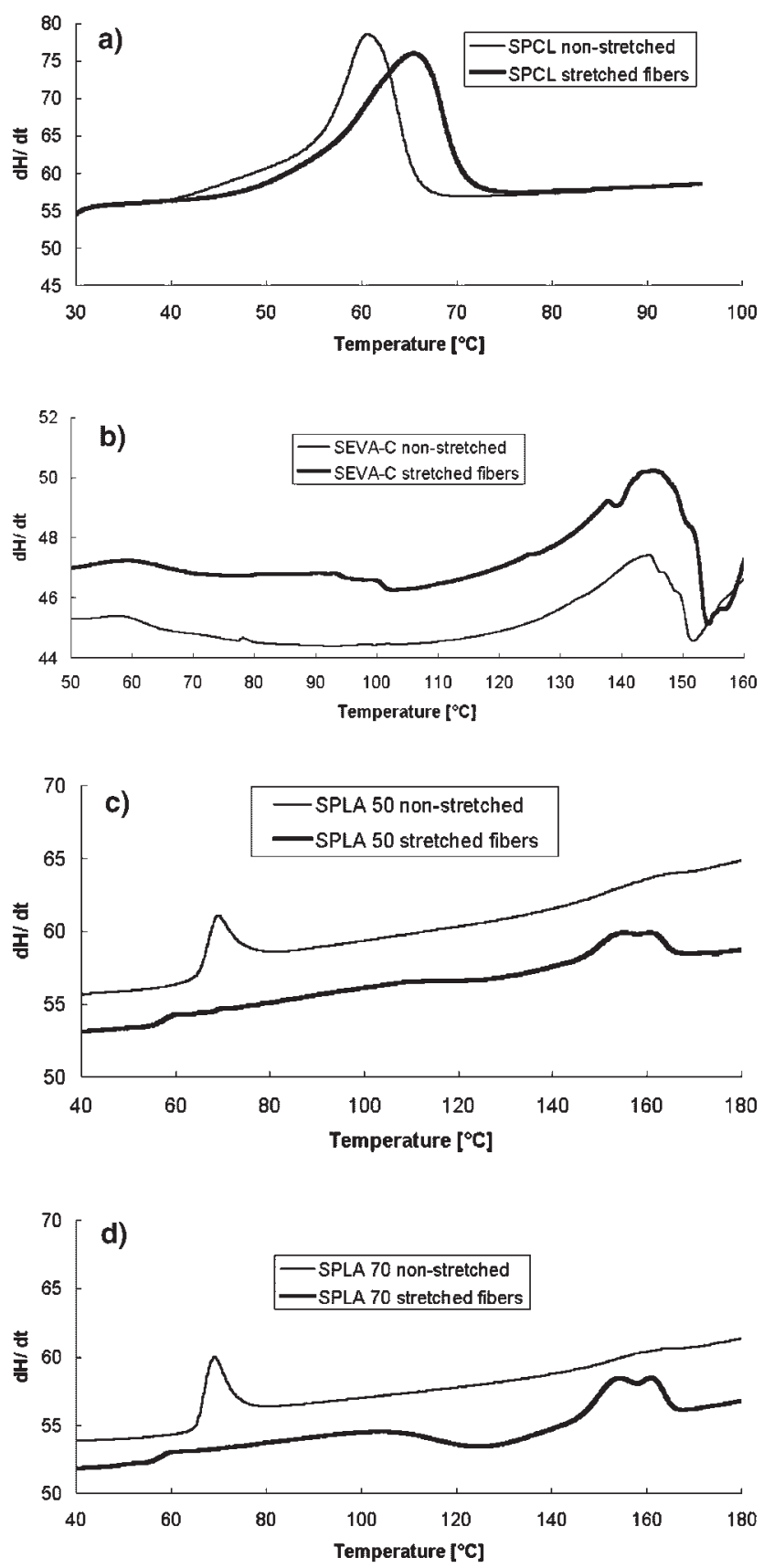

Figure 2. DSC traces of stretched and non-stretched fibers obtained for the various starch compounds: a) SPCL; b) SEVA-C; c) SPLA-50; d) SPLA-70.

for the SPLA blends. The melting temperature for pure PLA is about $180^{\circ} \mathrm{C}^{[18]}$ and in our case was $145.3^{\circ} \mathrm{C}$ for SPLA 70 and $145.4^{\circ} \mathrm{C}$ for SPLA 50 stretched fibers.

The SPCL blend showed the most stable mechanical behavior within the immersion time studied (Figure 3). This blend does not require high amounts of processing agents. The SPLA 70 blend showed a sharp decrease in stiffness, eventually associated with recovery of orientation caused by the plasticizing effect of the water. Further evolution of the stiffness of this blend after the initial drop may be caused 
Table 4. DSC results for stretched and non-stretched samples. The following symbols are used: $T_{\mathrm{g}}-$ glass-transition temperature; $T_{\mathrm{m}}-$ melting temperature; $\Delta H_{\mathrm{m}}-$ melting enthalpy; $W_{\mathrm{c}}$ - degree of crystallization calculated by Equation $(1), \Delta C_{\mathrm{p}}-$ change in the heat capacity, during the glass transition, $F$ - ratio between the components in the blend, $\Delta H_{0}$ - melting enthalpy for $100 \%$ crystalline polymer.

\begin{tabular}{|c|c|c|c|c|c|c|c|}
\hline & $T_{\mathrm{g}}$ & $T_{\mathrm{m}}$ & $\Delta C_{\mathrm{p}}$ & $\Delta H_{\mathrm{m}}$ & $W_{\mathrm{c}}$ & $\Delta H_{0}^{[17,24]}$ & $\mathrm{F}$ \\
\hline & ${ }^{\circ} \mathrm{C}$ & ${ }^{\circ} \mathrm{C}$ & $\mathrm{J} \cdot \mathrm{g}^{-1} \mathrm{~K}^{-1}$ & $\mathrm{~J} \cdot \mathrm{g}^{-1}$ & $\%$ & $\mathrm{~J} \cdot \mathrm{g}^{-1}$ & $\%$ \\
\hline SPCL str & - & 54.4 & - & 46.50 & 44.10 & 76.50 & 70 \\
\hline SPCL non-str & - & 53.9 & - & 48.20 & 42.55 & 76.50 & 70 \\
\hline SPLA $70 \mathrm{str}$ & 57.4 & 145.3 & 0.20 & 13.90 & 11.92 & 81.63 & 70 \\
\hline SPLA 70 non-str & 59.7 & 150.5 & 0.33 & 0.89 & 0.77 & 81.63 & 70 \\
\hline SPLA $50 \mathrm{str}$ & 57.0 & 145.4 & 0.17 & 8.20 & 5.03 & 81.63 & 50 \\
\hline SPLA 50 non-str & 62.8 & 154.2 & 0.33 & 0.50 & 0.31 & 81.63 & 50 \\
\hline SEVA-C str & - & 145.4 & - & 41.51 & - & - & 50 \\
\hline SEVA-C non-str & - & 144.6 & - & 29.06 & - & - & 50 \\
\hline
\end{tabular}

by loss of plasticizer agents and low molecular weight material. The stiffness increase corresponding to longer immersion times, while not statistically significant, may be associated with some increase in crystallinity, since the amorphous regions will be preferentially degraded. SEVA$\mathrm{C}$ shows also a large increase of stiffness caused by the loss of processing agents and low molecular weight material.

The glass-transition temperatures of the starch/PLA blend studied were $59.7^{\circ} \mathrm{C}\left(\Delta C_{\mathrm{p}}=0.33 \mathrm{~J} \cdot \mathrm{g}^{-1} \mathrm{~K}^{-1}\right)$ and $62.8^{\circ} \mathrm{C}\left(\Delta C_{\mathrm{p}}=0.33 \mathrm{~J} \cdot \mathrm{g}^{-1} \mathrm{~K}^{-1}\right)$ for the SPLA 70 and SPLA 50 initial materials. For the stretched fibers they were $57.4{ }^{\circ} \mathrm{C}\left(\Delta C_{\mathrm{p}}=0.20 \mathrm{~J} \cdot \mathrm{g}^{-1} \mathrm{~K}^{-1}\right)$ for SPLA 70 and $57.0^{\circ} \mathrm{C}$ $\left(\Delta C_{\mathrm{p}}=0.17 \mathrm{~J} \cdot \mathrm{g}^{-1} \mathrm{~K}^{-1}\right)$ for SPLA 50. Similar results were reported previously ${ }^{[18]}$ with a $T_{\mathrm{g}}$ of $59.2^{\circ} \mathrm{C}$ for SPLA 50 and $59.6^{\circ} \mathrm{C}$ for SPLA 70 powders from another batch source. Those values are consistently higher than the $T_{\mathrm{g}}$ for pure amorphous PLA $\left(54{ }^{\circ} \mathrm{C}\right) .{ }^{[19]}$ This result is connected with the change of the molecular mobility when the amorphous fraction is located between crystalline lamellae. ${ }^{[18]}$ Moreover, hydrogen bonding with the hydroxyl groups of starch may constrain the segmental mobility of the synthetic polymeric chains.

\section{Water Uptake and Degradation Behavior}

From Figure 4 it is possible to observe a higher water absorption by the SEVA-C and SPLA 50 fibers than by the

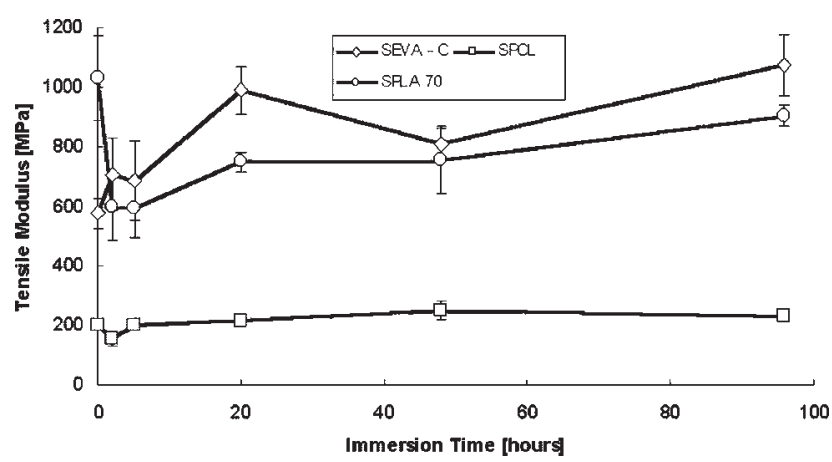

Figure 3. The influence of the immersion time in a $0.154 \mathrm{M} \mathrm{NaCl}$ solution on the tensile modulus of the fibers.
SPCL and SPLA 70 fibers. The difference in water uptake between SPLA 50 and SPLA 70 fibers can be explained by the fact that SPLA 70 has more PLA $(70 \%)$ than SPLA 50 (50\% PLA). Therefore SPLA 50 will be more hydrophilic than SPLA 70 due to the larger starch content. Following the same reasoning for SPCL, the PCL chains are more hydrophobic than EVOH or PLA. The hydroxyl groups are much more hydrophilic than the carbonyl group coming from PCL, supporting the observation that SPCL has lower water absorption than the other blends studied in this work. Besides the hydrophilic character, SPCL has the highest crystallinity degree, so a lower water uptake capability is expected for this material.

The limit value for the water uptake should be regarded as a result of two complementary phenomena: the intrinsic water uptake capability of the material (related to the chemical composition and crystallinity) and the degradation history of the material. Those phenomena are somewhat inter-related. This is the main reason why the water uptake should be discussed along with the weight loss behavior. It can be observed (Figure 4 ) that all the compounds have a maximum in the water uptake at the $5 \mathrm{~h}$ data point and stabilize at least at the $48 \mathrm{~h}$ data point. The maximum is probably related to the presence of starch in all the blends. The overall kinetics seem to be dominated by the starch fraction in the blend. The maximum shown in the curves of Figure 4 should also be related to the release of

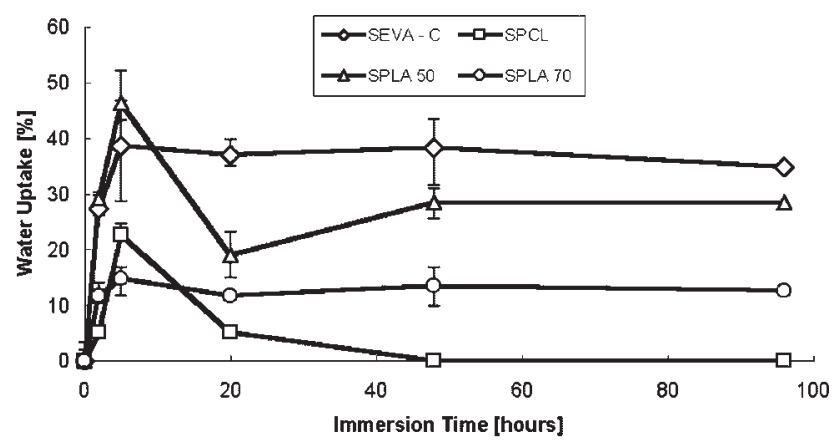

Figure 4. Water uptake of the fibers as a function of the immersion time. 


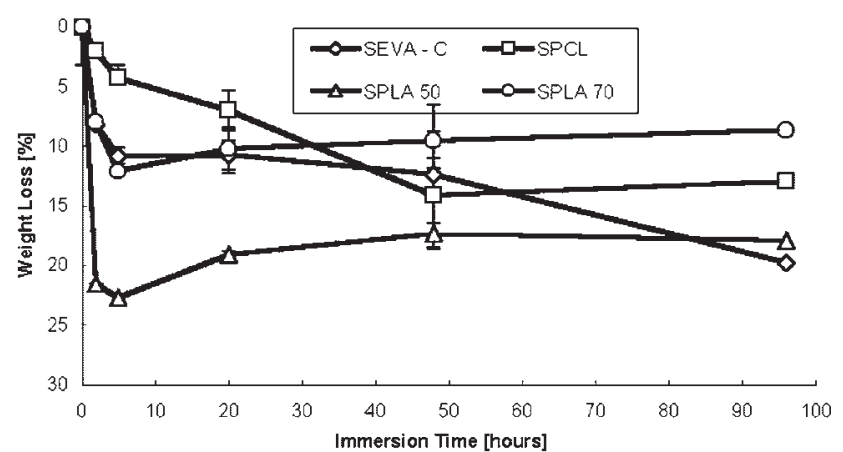

Figure 5. Weight loss of the fibers as a function of the immersion time.

low molecular weight material and processing additives in the first hours (see Figure 5). In fact, when comparing the maxima for SPLA 50 and SEVA-C (with the same amount of starch in the blend) it is observed that although the limit value for the water uptake of SEVA-C is higher, a larger peak value is shown in the SPLA 50 blend. This is consistent with the higher initial weight loss of SPLA-50 (Figure 5). This may also be a result of different contents of processing additives (typically polyglycols).

The results of weight loss are in general agreement with the results of the water uptake. Figure 5 shows that the SPLA 50 fibers lost twice the weight as compared to SPLA 70 , this clearly indicating that the starch fraction degrades faster than the PLA one. Also SPCL lost less weight than SPLA 50 and SEVA-C.

\section{Tensile Tests}

In general it can be said that the mechanical properties of the stretched fibers are significantly improved when compared with the mechanical properties of non-stretched fibers. It can be seen in Figure 6 and 7 that the stretched fibers exhibited from three to nine times higher tensile modulus. Comparing the values from Figure 6 and Figure 7, it can be seen that the modulus of SPCL stretched fibers $(201 \mathrm{MPa} \pm 15 \%)$ is 10 times higher than the modulus of non-stretched fibers $(20 \mathrm{MPa} \pm 10 \%)$. The same relation can be observed for stretched and non-stretched fibers made of SPLA 70 - the modulus for stretched fibers is approximately 9 times higher than the non-stretched. As was expected, SPLA 70 and SEVA-C fibers had the highest tensile modulus. SPCL fibers had the largest strain at break.

The highest modulus and tensile strength of the stretched fibers can also be interpreted with the help of DSC results. As can be seen in Table 4, the stretched fibers have higher crystalline content $\left(W_{\mathrm{c}}\right)$ and the degree of crystallization is directly correlated with the mechanical properties - a higher degree of crystallization leads to higher modulus and tensile strength. A similar direct relation can be observed when comparing the increase of $W_{\mathrm{c}}$ and the enhancement of the mechanical properties, namely modulus and tensile
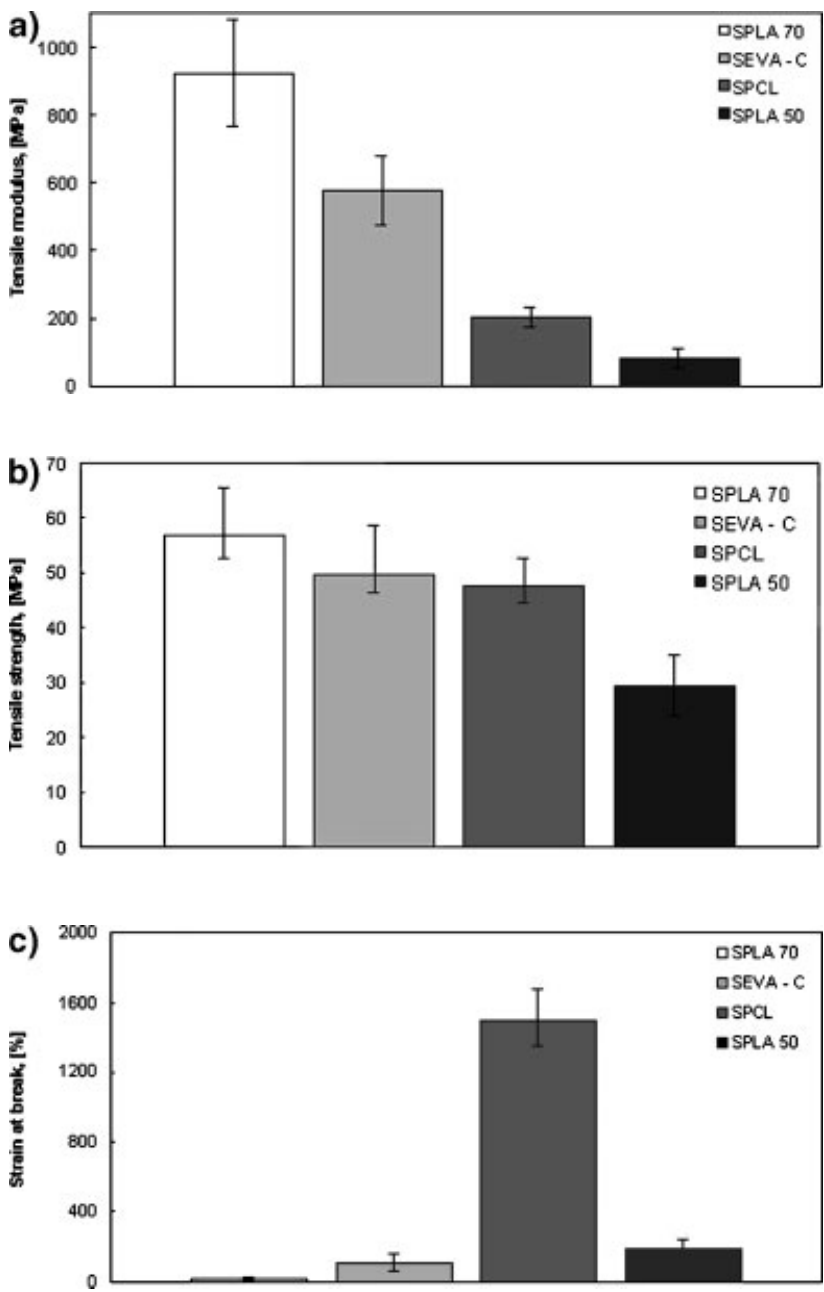

Figure 6. Mechanical properties of stretched fibers: a) tensile modulus; b) tensile strength; c) tensile strain at break.

strength, for SPLA 70 and SPCL after stretching. The increase of the mechanical properties of SPLA 70 after stretching is larger when compared with SPCL. This observation may be related to the higher degree of crystallization for SPLA 70 after stretching (Table 4). As well as the increase of crystallinity, the improvement of the mechanical properties may also be related to the enhancement of the orientation of the macromolecular chains.

Some surface irregularity can be observed at the fiber surface in SEM pictures (Figure 8). The irregular surface of the fibers can affect its mechanical properties which are much lower when compared with the mechanical properties of injection molded samples. ${ }^{[8,20-23]}$ The irregular surface could lead to stress concentration effects causing premature failure of the fibers. However, it is not clear why the stiffness of the fibers is much lower than the stiffness of injection molded parts. Matzinos et al. ${ }^{[17]}$ reported comparable values of modulus for SPCL, from 259 to $351 \mathrm{MPa}$ (depending on the amount of PCL in the blend), for samples produced by injection molding. Our result of $201 \mathrm{MPa}$, which is still lower than these results, could be due to the 

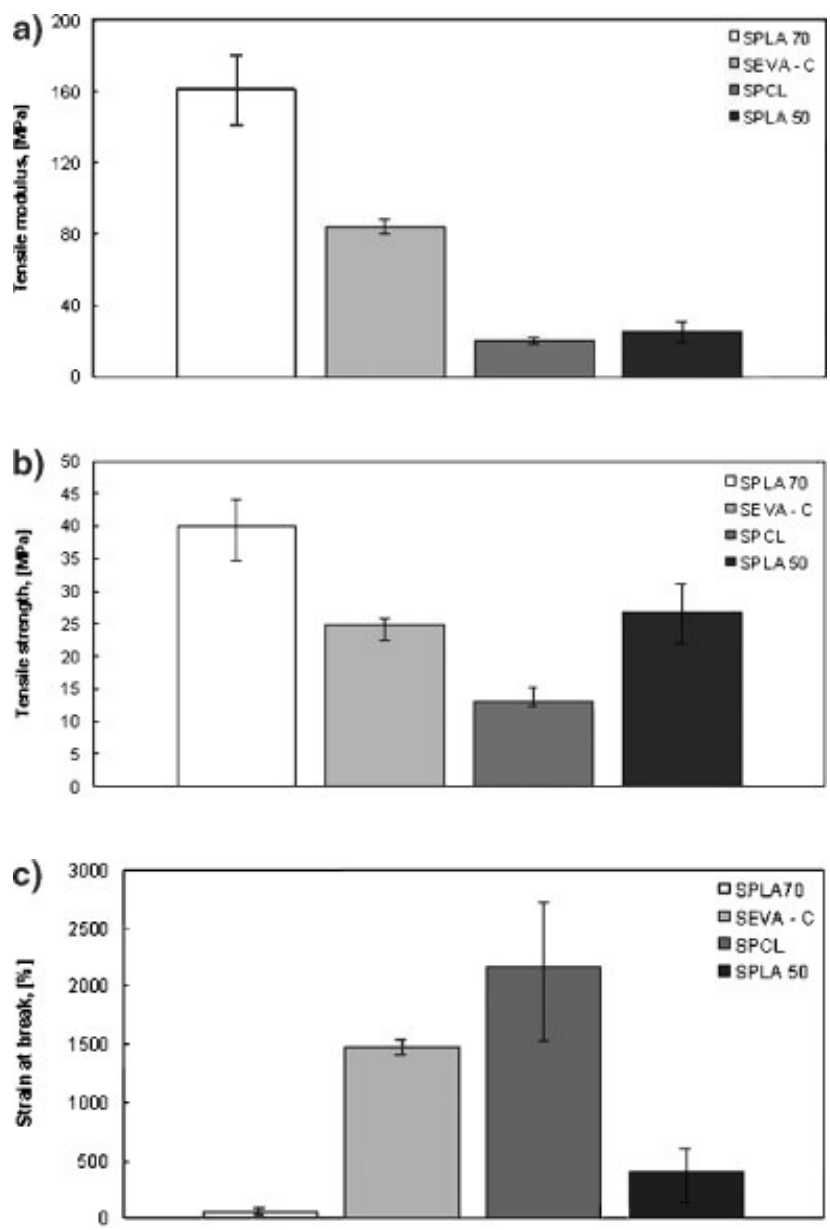

Figure 7. Mechanical properties of non-stretched fibers: a) tensile modulus; b) tensile strength; c) tensile strain at break.

specific processing routine used in our work in which the melt mixing/homogenization is probably not sufficiently effective.

The mechanical properties, namely the tensile modulus, do not exhibit notorious variation during the degradation period $(96 \mathrm{~h})$ as shown in Table 5.

The slight increase of the modulus at longer immersion periods could be explained by the initial loss of plasticizer and other processing aids, which was reported previously by other researchers. ${ }^{[24,25]}$ This behavior was also observed in the analysis of the dependence of the storage modulus with the degradation time obtained by dynamic mechanical analysis. ${ }^{[26]}$ The present results also show that after $20 \mathrm{~h}$ immersion, the materials undergo a degradation process characterized by a stabilization of the stiffness (see also Figure 3).

\section{Characterization of the 3D Porous Scaffolds}

\section{Porosity}

The results from the porosity assessment of the 3D scaffolds produced with the fibers are presented in Table 6 . The total a)

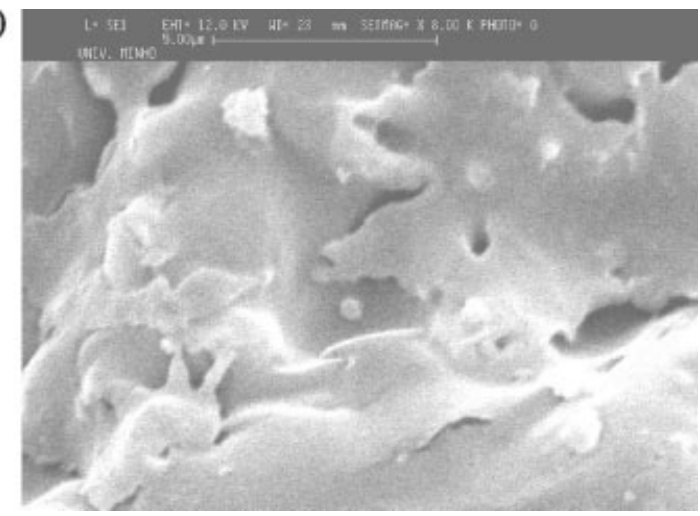

b)

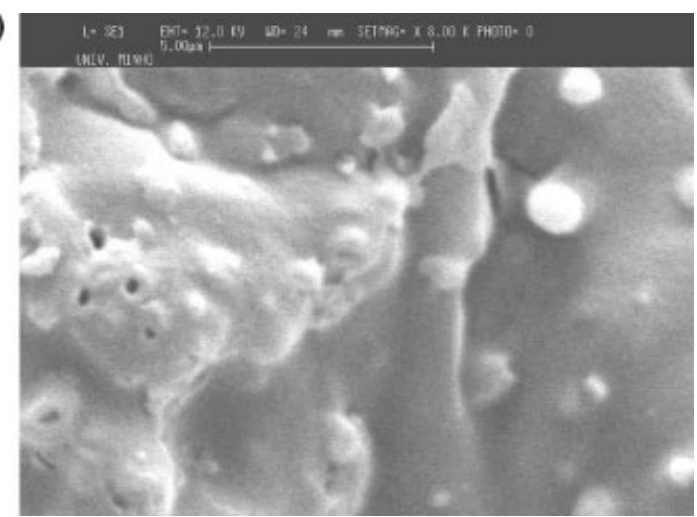

c)

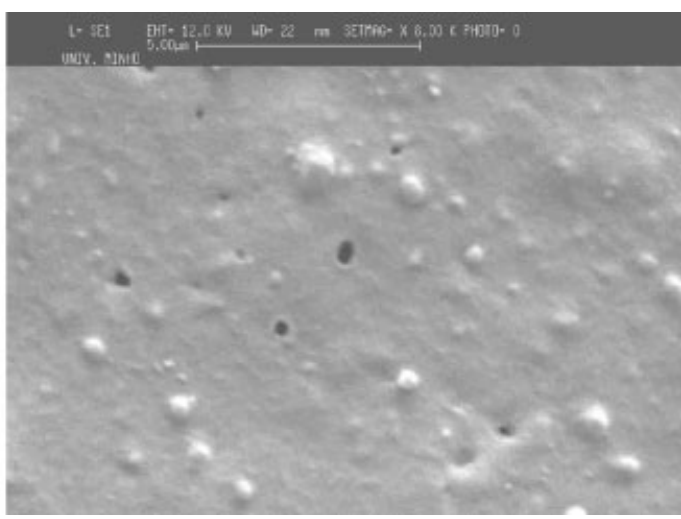

d)

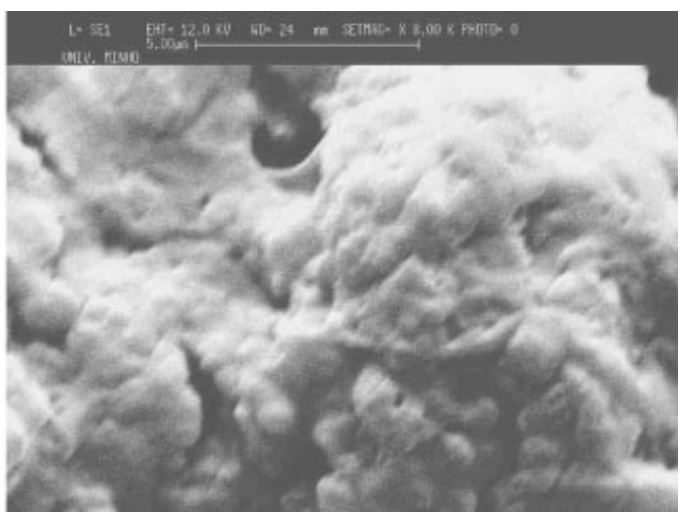

Figure 8. SEM micrographs of the surfaces of fibers: a) SPLA 50; b) SPLA70; c) SPCL; d) SEVA-C. 
Table 5. Tensile test results of stretched fibers after degradation test.

\begin{tabular}{|c|c|c|c|c|}
\hline Immersion time & Starch blend & Secant modulus at $1 \%$ strain & Tensile strength & Strain at break \\
\hline $\mathrm{h}$ & & $\mathrm{MPa}$ & $\mathrm{MPa}$ & $\%$ \\
\hline \multirow[t]{3}{*}{2} & SPCL & $156.0 \pm 80$ & $35.0 \pm 15.4$ & $177.08 \pm 30.5$ \\
\hline & SPLA 70 & $595.9 \pm 221$ & $38.7 \pm 8.5$ & $10.3 \pm 1.9$ \\
\hline & SEVA-C & $707.1 \pm 238.2$ & $41.4 \pm 8.6$ & $52.2 \pm 19.4$ \\
\hline \multirow[t]{3}{*}{5} & SPCL & $201.2 \pm 24.3$ & $37.1 \pm 12.6$ & $137.7 \pm 37.7$ \\
\hline & SPLA 70 & $591.7 \pm 164.8$ & $34.5 \pm 5.8$ & $11.6 \pm 4$ \\
\hline & SEVA-C & $624.5 \pm 264.1$ & $39.9 \pm 18.4$ & $33.4 \pm 15.2$ \\
\hline \multirow[t]{3}{*}{20} & SPCL & $216.7 \pm 31$ & $89.6 \pm 11.8$ & $162.9 \pm 66.5$ \\
\hline & SPLA 70 & $747.1 \pm 177.3$ & $34.3 \pm 4.5$ & $5.8 \pm 2.2$ \\
\hline & SEVA-C & $987.6 \pm 122.2$ & $43.4 \pm 7.6$ & $14.9 \pm 7.4$ \\
\hline \multirow[t]{3}{*}{48} & SPCL & $251.2 \pm 35.6$ & $26.8 \pm 4.3$ & $734.6 \pm 34.8$ \\
\hline & SPLA 70 & $753.6 \pm 226.7$ & $41.8 \pm 14.2$ & $7.1 \pm 2.8$ \\
\hline & SEVA-C & $807.5 \pm 107.8$ & $78.9 \pm 8.7$ & $36.5 \pm 15.8$ \\
\hline \multirow[t]{3}{*}{96} & SPCL & $229.0 \pm 23.9$ & $37.5 \pm 8.7$ & $104.5 \pm 33.9$ \\
\hline & SPLA 70 & $902.5 \pm 74.9$ & $51.0 \pm 6.4$ & $8.5 \pm 2.7$ \\
\hline & SEVA-C & $1072.5 \pm 123.5$ & $58.0 \pm 7.3$ & $15.6 \pm 1.8$ \\
\hline
\end{tabular}

porosity observed was about $68 \%$ (compared to the whole area of the measured sample), $38 \%$ of which referred to interconnected pores. Haire et al. reported porosities from 37 to $77 \%$ for equine cancellous bone ${ }^{[27]}$ and Specchia et al. ${ }^{[28]}$ argued that high porosity is more favorable for cell adhesion. In Figure 9, the morphology of the developed scaffolds can be observed as well as the porous distribution in the mesh obtained from SPLA 70 fibers.

\section{Degradation Behavior}

The degradation behavior study included the follow up of the water uptake and of the weight loss during a $32 \mathrm{~d}$ period of immersion in isotonic saline solution. The results are summarized in Figure 10 and 11. The water uptake curve (Figure 10) of the 3D mesh is similar to the water uptake curve of SPLA 70 fibers (Figure 4). It shows that the processing procedure used did not change the degradation properties of the material. However, the water uptake is higher because the $3 \mathrm{D}$ mesh construct can retain much more water than the fibers.

A comparison between the values of weight loss for SPLA 70 fibers and 3D porous scaffolds (to be observed by comparing Figure 5 to Figure 11) shows that the material has an almost constant weight loss after $4 \mathrm{~d}$ in the isotonic saline solution. This result was expected because, in fact, the production routine of the $3 \mathrm{D}$ mesh scaffolds was the

Table 6. Porosity of 3D fiber meshes produced from SPLA 70.

SPLA $70-3$ D porous scaffolds made of fibers

\begin{tabular}{ll}
\hline Total Porosity (\%) & 67.8 \\
Interconnected pores $(\%)$ & 25.0 \\
Interconnected pores compared & 36.8 \\
$\quad$ to total porosity $(\%)$ & \\
\hline
\end{tabular}

same as the one used for the fibers. However, it is interesting to note that the 3D mesh has a slightly lower weight loss than the SPLA 70 fibers.

\section{Conclusions}

The results obtained show that all the different starch based blends investigated in this work are suitable for the production of biodegradable fibers with adequate diameter and mechanical properties by means of a technique based on melt spinning.

It was shown that the technique can be easily adapted for the fabrication of $3 \mathrm{D}$ porous meshes with appropriate porosity and interconnectivity for tissue engineering.

The mechanical properties before and after the degradation tests of the blends under study - SPCL, SPLA 50, SPLA 70 and SEVA-C fibers and 3D porous scaffolds made of SPLA 70 fibers have similar trends.

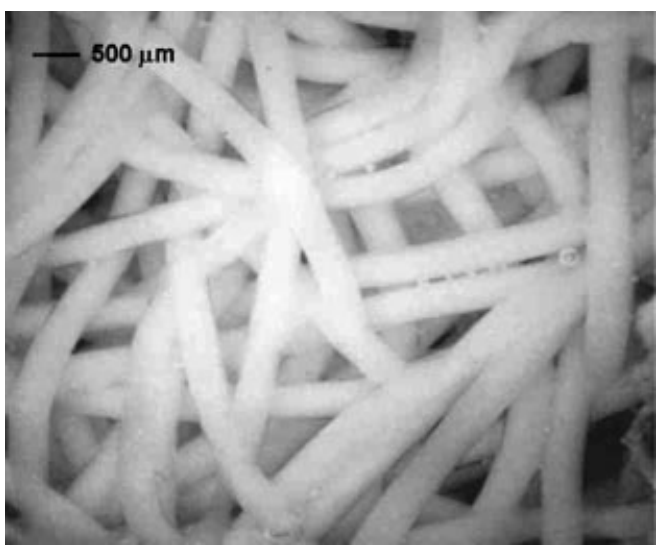

Figure 9. Light microscopy pictures of the 3D meshes obtained from SPLA 70 fibers. 


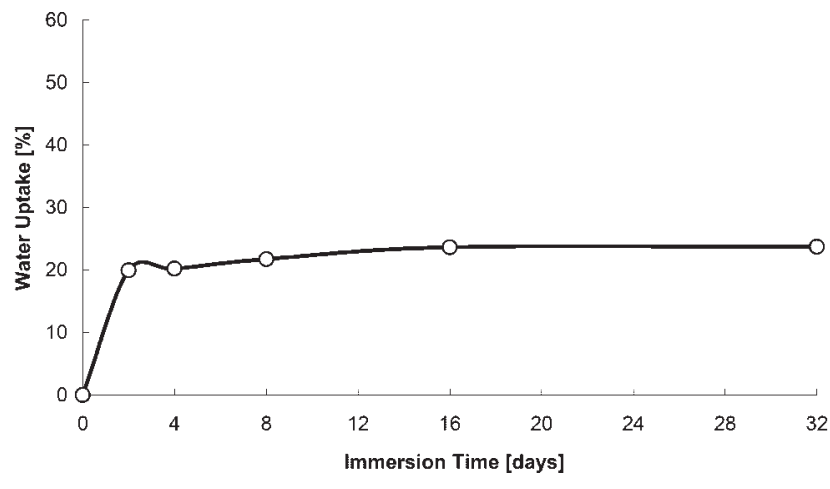

Figure 10. Water uptake of the 3D meshes obtained from SPLA 70 fibers.

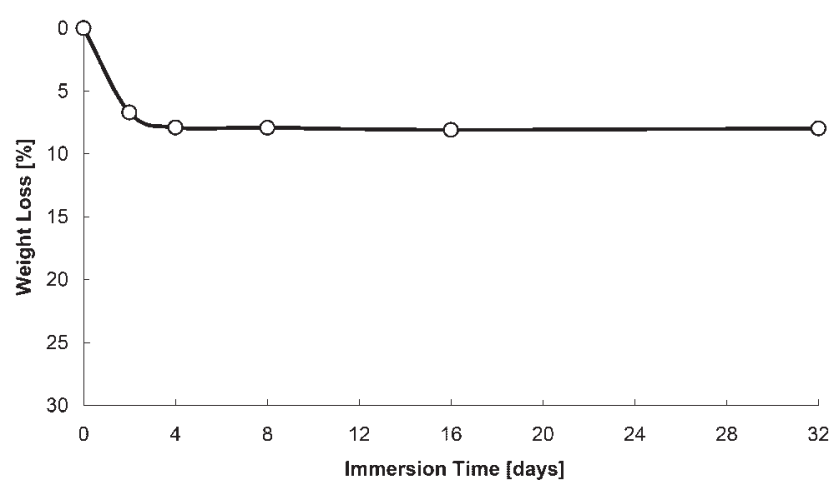

Figure 11. Weight loss of the 3D meshes obtained from SPLA 70 fibers.

It was shown that, during the processing, an increase of the degree of crystallization was detected, which is responsible for the improvement of the mechanical properties of the fibers after stretching.

Fibers manufactured from different starch-based blends exhibited significant differences in their mechanical and degradation behavior, which could make them suitable for different tissue engineering scaffolding applications.

[1] L. E. Freed, G. Vunjak-Novakovic, Adv. Drug Deliv. Rev. 1998, 33, 15.

[2] K. J. L. Burg, S. Porter, J. F. Kellam, Biomaterials 2000, 21, 2347.
[3] R. C. Thomson, M. C. Wake, M. Yaszemski, A. G. Mikos, Adv. Polym. Sci. 1995, 122, 247.

[4] R. Langer, J. Controlled Release 1999, 62, 7.

[5] L. Lu, A. G. Mikos, MRS Bull. 1996, 21, 28.

[6] R. Langer, J. R. Vacanti, Science 1993, 260, 920.

[7] R. Zhang, P. X. Ma, J. Biomed. Mater. Res. 1999, 44, 446.

[8] W. W. Minuth, M. Sitzinger, S. Kloth, Cell Tissue Res. 1998, $291,1$.

[9] M. E. Gomes, A. S. Ribeiro, P. B. Malafaya, R. L. Reis, A. M. Cunha, Biomaterials 2001, 22, 883.

[10] K. A. Athanasiou, J. D. Heckman, Mater. Sci. Forum 1997, $250,115$.

[11] R. Thomson, M. Yaszemski, A. G. Mikos, "Polymer Scaffolds Processing”, in: Principles of Tissue Engineering, R. Lanza, R. Langer, W. Chick, Eds., Academic Press, New York 1997, p. 263.

[12] P. B. Malafaya, C. Elvira, A. Gallardo, J. San Romàn, R. L. Reis, J. Biomater. Sci. Polymer Edn. 2001, 12, 1227.

[13] N. Rotter, J. Aigner, A. Nauman, H. Planck, C. Hammer, G. Burmester, M. Sittinger, J. Biomed. Mater. Res. 1998, 42, 347.

[14] R. Beyreuther, H. Hofmann, "Cause-effect-relations between technological parameters and geometrical or structural properties of PET-hollow fibers in the melt spinning process", Polymer Processing Society $15^{\text {th }}$ Annual Meeting, Hertogenbosch, The Netherlands 1999.

[15] G. Schmack, D. Jehnichen, R. Vogel, B. Tändler, R. Beyreuther, S. Jacobsen, H.-G. Fritz, J. Biotech. 2001, 86, 151.

[16] R. Mani, M. Bhattacharya, Eur. Polym. J. 1998, 34, 1477.

[17] P. Matzinos, V. Tserki, A. Kontoyiannis, C. Panayiotou, Polym. Degrad. Stab. 2002, 77, 17.

[18] J. F. Mano, D. Koniarova, R. L. Reis, J. Mat. Sci.: Mat. Med. 2003, 04, 127.

[19] S. Jacobsen, H. G. Fritz, Polymer Eng. Sci. 1996, 36, 2799.

[20] R. L. Reis, A. M. Cunha, J. Mater. Sci.: Mat. Med. 1995, 6, 786.

[21] M. E. Gomes, J. S. Godinho, D. Tchalamov, A. M. Cunha, R. L. Reis, J. Applied Medical Polymers 2002, 6, 75.

[22] R. L. Reis, A. M. Cunha, P. S. Allan, M. J. Bevis, J. Polymer and Advanced Technology 1996, 7, 784.

[23] R. A. Sousa, G. Kalay, R. L. Reis, A. M. Cunha, M. J. Bevis, Journal of Applied Polymer Science 2000, 77, 1303.

[24] C. M. Vaz, R. L. Reis, A. M. Cunha, Mat. Res. Innovat. 2001, 4, 375.

[25] M. A. Araújo, C. M. Vaz, A. M. Cunha, M. Mota, Polym. Degrad. Stab. 2001, 73, 237.

[26] J. F. Mano, R. L. Reis, A. M. Cunha, J. Appl. Polym. Sci. 2000, 78, 2345.

[27] T. J. Haire, R. Hodgskinson, P. S. Ganney, C. M. Langton, Medical Engineering and Physics 1998, 20, 588.

[28] N. Specchia, A. Pagnotta, F. Greco, Key Engineering Materials 2000, 192-1, 355. 